\title{
PERBEDAAN OPTIC NERVE SHEATH DIAMETER (ONSD) PADA RESPONDEN NORMAL DAN NYERI KEPALA
}

\section{THE DIFFERENTIATION OPTIC NERVE SHEATH DIAMETER (ONSD) AT THE NORMAL VOLUNTEER AND HEADACHE}

\author{
Sulistyani Sulistyani ${ }^{1}$, Rivan Danuaji ${ }^{2}$ \\ ${ }^{1}$ Staff Neurologi Fakultas Kedokteran Universitas Muhammadiyah Surakarta \\ ${ }^{2}$ Staff Neurologi Fakultas Kedokteran Universitas Sebelas Maret Surakarta \\ Korespondensi : dr. Sulistyani, Sp.N. Email : sul271@ums.ac.id
}

\begin{abstract}
ABSTRAK
Nyeri kepala merupakan salah satu tanda adanya peningkatan tekanan intrakranial. Peningkatan tekanan intrakranial dapat menyebabkan pelebaran optic nerve sheath diameter (ONSD). ONSD dapat diukur dengan transorbital sonografi yang bersifat non-invasif. Tujuan penelitian ini untuk mengetahui perbedaan nilai ONSD pada responden normal dan nyeri kepala. Penelitian ini menggunakan pendekatan observasional analitik dengan metode cross sectional. Responden diambil dari pasien rawat inap dan responden normal. Hasil penelitian didapatkan Rata - rata nilai ONSD pada pasien nyeri kepala adalah $0,52 \pm 0,86$ dan pada responden normal adalah 0,40 $\pm 0,57(p<0,05)$. Terdapat perbedaan signifikan nilai ONSD pada pasien normal dan nyeri kepala, sehingga peningkatan intrakranial pada pasien nyeri kepala dapat dideteksi dengan pemeriksaan ONSD yang bersifat non-invasif.
\end{abstract}

Kata Kunci: Optic Nerve Sheath Diameter, Nyeri Kepala, Peningkatan Tekanan Intrakranial

\begin{abstract}
Headache is one of the symptoms of increased intracranial pressure. Increased intracranial pressure affects the optic nerve sheath diameter (ONSD) dilatation. Opticus nerve can be examined from ONSD dilatation examination by non invasif sonography transorbital. The research aimed to defferentiate the optic nerve sheath diameter (ONSD) on the normal volunteer and headache. Analysis observational with cross sectional method was conducted in ward patients with headache at RSDM in April-May 2015. Mean ONSD in headache patient is $0,52 \pm 0,86$ and normal volunteers $0,40 \pm 0,57(p<0,05)$. The significant different ONSD value between headache and normal volunteers, so intracranial increased on headache can be detected with non invasif ONSD examination.
\end{abstract}

Keyword: Optic Nerve Sheath Diameter, Headache, Intrakranial Pressure

How To Cite: Sulistyani. S., \& Danuaji, R. (2019). PERBEDAAN OPTIC NERVE SHEATH DIAMETER (ONSD) PADA RESPONDEN NORMAL DAN NYERI KEPALA. Biomedika, 11(2), 96-104. doi:https://doi.org/10.23917/biomedika.v11i2.8466

DOI: https://doi.org/10.23917/biomedika.v11i2.8466 


\section{PENDAHULUAN}

Nyeri kepala didefinisikan sebagai nyeri atau rasa tidak nyaman antara orbita dan occiput, akibat adanya stimulus pada struktur/bangunan peka nyeri. Secara umum, nyeri kepala dibagi menjadi nyeri kepala primer dan sekunder. Terminologi nyeri kepala primer digunakan jika sebagian besar etiologi dan patogenesisnya tidak diketahui atau nyeri kepala tersebut merupakan problem penyakitnya sendiri, sementara nyeri kepala sekunder merupakan gejala dari penyakit yang mendasarinya (Fernández-de-las-Peñas et al., 2010).

Nyeri kepala merupakan salah satu tanda peningkatan tekanan intrakranial (TIK), tergantung penyebabnya. Adanya peningkatan TIK akan mempengaruhi prognosis (outcome) suatu penyakit. Dengan mengetahui peningkatan TIK lebih awal mampu melakukan penatalaksanaan dengan tepat (Fuller et al., 2010).

Ultrasonografi transorbital merupakan salah satu pemeriksaan untuk mengetahui peningkatan TIK dengan deteksi pelebaran ONSD. Evaluasi adanya peningkatan TIK juga dapat dilakukan dengan : pemeriksaan tekanan LCS dengan lumbal pungsi, CT Scan,
Ventrikulostomi dan Funduskopi (papil edema)

(Amini et al., 2013).

Dilatasi ONSD tergantung pada tekanan ruang subarachnoid dan bukan berasal dari ONS. Perubahan tekanan $5 \mathrm{mmHg}$ di ruang subarachnoid akan membuka selubung myelin (sheath). ONSD seharusnya dapat digunakan untuk deteksi perubahan kecil (dilatasi awal) karena range tekanan likuor cerebrospinal yang rendah. Sebagian besar studi klinis melaporkan dilatasi ONSD dengan nilai ambang bervariasi.

Namun, ketika tekanan meningkat lebih tinggi $(50 \mathrm{mmHg}$ atau lebih) menyebabkan dilatasi ONSD $140 \%$ dari ukuran awal. Penelitian sebelumnya menyebutkan pemeriksaan ONSD direkomendasikan untuk dilakukan di Unit gawat darurat dan Intensive Care.

Dilatasi ONSD berasal dari jaringan dura, dapat dijelaskan sebagai berikut: 1) Elemen ONS terdapat ruang terbuka dan kolap pada awalnya sehingga adanya peningkatan tekanan akan membuka ruang tersebut; 2) ONS mempunyai struktur yang elastis yang dapat distensi dengan cepat, berbeda dengan tipe duramater. 
Studi untuk mengetahui kemampuan retraksi/distensi ONS dilakukan karena pada beberapa kasus ONS tidak kembali pada ukuran normal setelah dilakukan normalisasi tekanan intrakranial (hysteresis). ONSD tidak dapat kembali pada ukuran semula jika kenaikan tekanan subarachnoid $55 \mathrm{mmHg}$ atau lebih (bahkan beberapa mulai pada tekanan 35mmHg) karena kerusakan (overdistensi) trabekular ONS (Hansen et al., 2011).
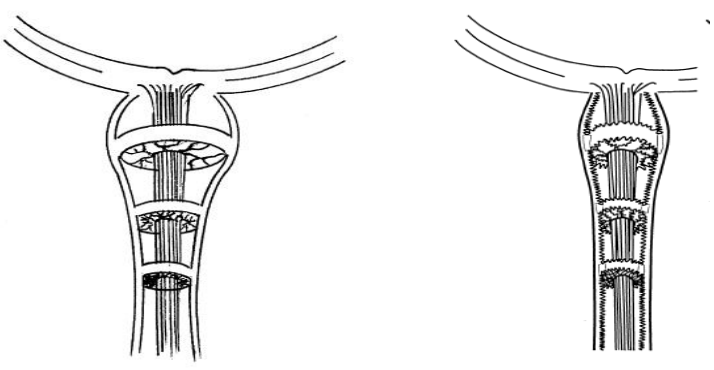

A

B

Gambar 1. A: ONSD Normal; B: ONSD dilatasi (Hansen, 2011)

Peningkatan TIK pada pemeriksaan ONSD dapat diketahui lebih dini daripada pemeriksaan menggunakan opthalmoskop. Pemeriksaan Funduskopi tidak reliabel untuk evaluasi pada jam-jam pertama terjadinya perubahan nervus optikus karena peningkatan TIK. Pemeriksaan TIK dengan cara pengukuran tekanan Likuor Cerebrospinal (LCS) merupakan tindakan agresif dan tergantung problem klinis serta kesediaan secara pribadi. Teknik ini juga memerlukan persiapan dan alat dimana sering diagnosis peningkatan TIK menjadi tertunda sementara memerlukan penatalaksanaan yang tepat selanjutnya (intervensi) (Amini et al., 2013).

Sonografi ONSD merupakan metode yang sederhana, non invasif, tidak mahal dan aman untuk mengetahui adanya peningkatan TIK, baik pada pasien trauma kepala maupun stroke (Amini et al., 2013). Penelitian Hansen et al. ( 2011) tentang akurasi pemeriksaan ONSD oleh dokter IGD yang telah mendapat kursus singkat oleh sonografer terlatih. Pemeriksaan sebelumnya telah divalidasi oleh sonografer terlatih tersebut. Hasil pemeriksaan dokter IGD dibandingkan dengan hasil CT Scan dan disimpulkan bahwa pemeriksaan ONSD dapat dilakukan oleh dokter dengan pelatihan minimal, cepat dan murah serta sangat bermanfaat untuk pasien di unit gawat darurat/intensive care unit (ICU) yang tidak transportable dilakukan CT Scan. Penelitian ini bertujuan untuk mengetahui perbedaan ONSD pada responden normal dan nyeri kepala. 


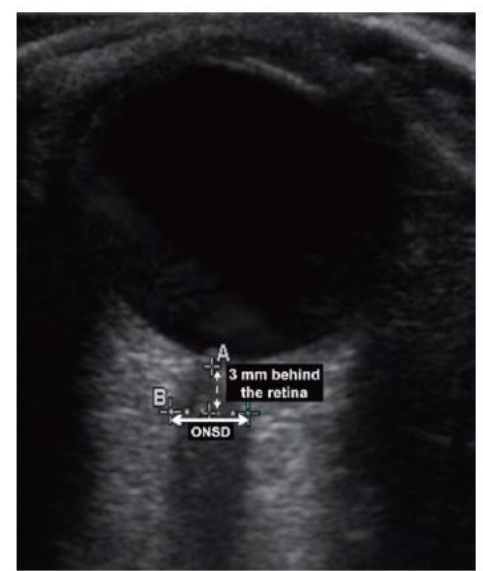

Gambar 2. Pemeriksaan ONSD dengan transorbital sonografi (Dubost, 2012)

\section{METODE}

Penelitian ini menggunakan desain observasional analitik dengan pendekatan cross sectional. Tempat penelitian dilakukan di RS. X Surakarta pada bulan April - Mei 2015. Sampel diambil secara random dengan perhitungan jumlah sampel minmal 25 dan ditetapkan pada penelitian ini 30 sampel pasien dengan nyeri kepala dan 30 responden normal. Seluruh sampel dilakukan pemeriksaan ONSD dengan ultrasonografi transorbital. Pasien nyeri kepala ditentukan berdasarkan keluhan pasien dengan pengukuran VAS (visual analogue score) dengan skala ordinal ringan (VAS 1-3), sedang (VAS 4-6) dan berat (VAS 7-10). Pada pasien nyeri kepala juga ditentukan berdasarkan onset nyeri akut jika $\leqq 3$ bulan dan kronis jika> 3 bulan. Hasil pemeriksaan ONSD didapatkan dari jarak area hiperechoic yang diukur secara horizontal $3 \mathrm{~mm}$ dibelakang retina pada pemeriksaan transorbital sonografi. Kriteria ONSD didapatkan normal jika ONSD $\leq 5,5 \mathrm{~mm}$ dan meningkat : ONSD > 5,5 mm. Analisa data yang digunakan dalam penelitian ini adalah analisa data dengan program SPSS 20 for windows. Untuk menghitung statistik digunakan uji Chi Square. Interpretasi hasil dari uji t tersebut, dinyatakan bermakna jika nilai $\mathrm{p}<0,05$ dan dinyatakan tidak bermakna jika nilai $\mathrm{p}>0,05$.

\section{HASIL DAN PEMBAHASAN}

Karakteristik responden terdapat pada tabel 1. Tabel tersebut menyebutkan bahwa presentasi nyeri kepala pada laki-laki lebih besar daripada pada perempuan yaitu sebesar 58,3\%. Analisis deskriptif jumlah pasien nyeri kepala dan responden normal menunjukkan nilai $\mathrm{p} 0,430(\mathrm{p}>0,05)$ artinya tidak terdapat perbedaan signifikan antara dua kelompok, sehingga dapat disimpulkan bahwa sampel homogen menurut jenis kelamin.

Tabel 1. Karakteristik Responden Penelitian

\begin{tabular}{lccc}
\hline & $\begin{array}{c}\text { Pasien Nyeri } \\
\text { Kepala } \\
(\mathbf{n = 3 0})\end{array}$ & $\begin{array}{c}\text { Responden } \\
\text { normal } \\
(\mathbf{n = 3 0})\end{array}$ & $\begin{array}{c}\text { Nilai } \\
\boldsymbol{p}\end{array}$ \\
\hline Jenis kelamin (\% laki-laki) & 58,3 & 41,7 & 0,430 \\
Usia (mean, range; tahun) & $49(19-76)$ & $35(26-59)$ & 0,000 \\
ONSD (mean \pm SD; mm) & $5,2 \pm 0,95$ & $4,2 \pm 0,66$ & 0,000 \\
R-IMT (mean \pm SD; mm) & $0,65 \pm 0,18$ & $0,58 \pm 0,20$ & 0,171 \\
L-IMT (mean \pm SD; $\mathrm{mm})$ & $0,67 \pm 0,19$ & $0,57 \pm 0,14$ & 0,029 \\
Sistolik (mean $\pm \mathrm{SD} ; \mathrm{mmHg})$ & $138 \pm 22,3$ & $116 \pm 13,80$ & 0,000 \\
\hline
\end{tabular}




\begin{tabular}{|c|c|c|}
\hline Diastolik (mean $\pm \mathrm{SD} ; \mathrm{mmHg}$ ) & $86 \pm 8,94$ & $74 \pm 8,17$ \\
\hline \multicolumn{3}{|l|}{ Derajat Nyeri } \\
\hline - Ringan (n;\%) & $24 ; 80$ & - \\
\hline - Sedang $(\mathrm{n} ; \%)$ & $4 ; 13,3$ & - \\
\hline - Berat $(\mathrm{n} ; \%)$ & $2 ; 6,7$ & - \\
\hline \multicolumn{3}{|l|}{ Onset Nyeri } \\
\hline - Akut (n;\%) & $23 ; 76,7$ & - \\
\hline - Kronis $(\mathrm{n} ; \%)$ & $7 ; 23,3$ & - \\
\hline \multicolumn{3}{|l|}{ Jenis Penyakit } \\
\hline - Migren (n;\%) & $2 ; 6,7$ & - \\
\hline - TTH $(\mathrm{n} ; \%)$ & $3 ; 10$ & - \\
\hline - SAH $(\mathrm{n} ; \%)$ & $1 ; 3$ & - \\
\hline$-\operatorname{ICH}(\mathrm{n} ; \%)$ & $4 ; 13$ & - \\
\hline - SNH $(\mathrm{n} ; \%)$ & $11 ; 36,7$ & - \\
\hline$-\operatorname{SOL}(\mathrm{n} ; \%)$ & $5 ; 17$ & - \\
\hline - Hidrocephalus (n ; \%) & $2 ; 6,7$ & - \\
\hline - Hipertensi $(\mathrm{n} ; \%)$ & $2 ; 6,7$ & - \\
\hline
\end{tabular}

Rata-rata usia pasien nyeri kepala pada penelitian ini adalah 49 tahun dengan range usia 19-76 tahun, sedangkan rata-rata usia pada responden normal adalah 32 tahun dengan range usia 22-59 tahun. Nilai $\mathrm{p}$ kelompok nyeri kepala dan responden normal adalah 0,000 (p $<0,05)$, artinya berbeda signifikan antara dua kelompok.

Rata-rata nilai ONSD pasien nyeri kepala pada penelitian ini adalah $5,2 \pm 0,95$ mm, sedangkan rata-rata nilai ONSD pada responden normal adalah 4,2 $\pm 0,66 \mathrm{~mm}$ dengan nilai $\mathrm{p}<0,05$ artinya berbeda signifikan antara dua kelompok.

Pemeriksaan ketebalan intima media (IMT) kanan nilai p 0,171 (p < 0,5) dan 0,029 ( $\mathrm{p}<0,05)$, artinya IMT kanan tidak berbeda secara signifikan (homogen) sedangkan IMT kiri berbeda signifikan antara kedua kelompok (tidak homogen).
Pemeriksaan tekanan darah baik sistolik maupun diastolik menunjukkan nilai $\mathrm{p}$ 0,000 dan $0,000(\mathrm{p}<0,05)$ artinya berbeda secara signifikan antara dua kelompok. Menurut derajat nyeri distribusi yang terbanyak pada sampel adalah nyeri ringan $(80 \%)$ dan paling sedikit nyeri berat $(6,7 \%)$. Menurut onsetnya sampel dengan nyeri kapala akut $(76,7)$ mempunyai prosentase lebih besar daripada nyeri kepala kronis (23,3\%). Berdasarkan jenis penyakit, stroke non hemogarik (SNH) mempunyai jumlah terbanyak $(36,7 \%)$ dan paling sedikit adalah pasien SAH (3\%).

Analisis nilai ONSD pada pasien nyeri kepala dan responden normal menunjukkan nilai p 0,001 $(\mathrm{p}<0,05)$ artinya bahwa terdapat perbedaan signifikan nilai ONSD pada pasien nyeri kepala dan responden normal (tabel 2).

Tabel 2 Nilai ONSD pada pasien nyeri kepala dan responden normal

\begin{tabular}{lccc}
\hline & $\begin{array}{c}\text { ONSD } \\
\text { Meningkat }\end{array}$ & $\begin{array}{c}\text { ONSD } \\
\text { Normal }\end{array}$ & $\begin{array}{c}\text { Nilai } \\
\boldsymbol{p}\end{array}$ \\
\hline $\begin{array}{l}\text { Nyeri kepala } \\
(\mathrm{n}(\%))\end{array}$ & $14(46,7 \%)$ & 16 & 0,001 \\
$\begin{array}{l}\text { Responden } \\
\text { Normal }(\mathrm{n}(\%))\end{array}$ & $2(6,7 \%)$ & $(53,3 \%)$ & \\
\hline
\end{tabular}

Analisis nilai ONSD pada pasien nyeri kepala ringan menunjukkan nilai $p=0,001(\mathrm{p}<$ $0,05)$, nyeri kepala sedang p 0,322 ( > 0,05) 
dan nyeri kepala berat p 0,12 $(<0,05)$. Artinya

adanya perbedaan signifikan antara kelompok

normal dan nyeri kepala ringan/berat,

sedangkan pada nyeri kepala sedang tidak

terdapat perbedaan diantara dua kelompok

(tabel 3). Perhitungan Positive Predictive

Value (PPV) didapatkan 87,5\% dan Negative

Predictive Value (NPV) 63,63\%.

Tabel 3 Analisis Nilai ONSD pada nyeri kepala

\begin{tabular}{lccc}
\hline & $\begin{array}{c}\text { ONSD } \\
\text { Normal }\end{array}$ & $\begin{array}{c}\text { ONSD } \\
\text { Meningkat }\end{array}$ & $\begin{array}{c}\text { Nilai } \\
\boldsymbol{p}\end{array}$ \\
\hline $\begin{array}{l}\text { Normal (n=30) } \\
\text { Derajat nyeri }\end{array}$ & 28 & 2 & \\
- Ringan (n=24) & $13(54,2 \%)$ & $11(45,8 \%)$ & 0,001 \\
- Sedang (n=4) & $3(75 \%)$ & $1(25 \%)$ & 0,322 \\
- Berat (n=2) & $0(0 \%)$ & $2(100 \%)$ & 0,012 \\
Onset nyeri & & & \\
- Akut (n=23) & $15(65,2 \%)$ & $8(34,8 \%)$ & 0,014 \\
- Kronis (n=7) & $1(14,3 \%)$ & $6(85,7 \%)$ & 0,000 \\
\hline
\end{tabular}

Berdasarkan onset nyeri didapatkan nilai $\mathrm{p} 0,14(\mathrm{p}<0,05)$ pada nyeri kepala akut dan p 0,000 $(\mathrm{p}<0,05)$ pada nyeri kepala kronis, artinya terdapat perbedaan signifikan pada kedua kelompok tersebut dibandingkan dengan responden normal (tabel 3).

Berdasarkan tabel 1 distribusi jenis kelamin pada kedua kelompok mempunyai nilai $\mathrm{p} 0,430(\mathrm{p}>0,05)$, artinya tidak terdapat perbedaan signifikan antara dua kelompok tersebut. Adanya distribusi jenis kelamin yang homogen pada kedua kelompok diharapkan tidak mempengaruhi hasil penelitian.
Adanya distribusi sampel menurut usia yang tidak homogen pada kelompok nyeri kepala dan responden normal (tabel 1) tidak mempengaruhi hasil analisis data. Hal ini sesuai dengan penelitian sebelumnya yang menyebutkan bahwa ONSD normal pada anak $<4,3 \mathrm{~mm}$ (Beare et al., 2012) dan pada dewasa (diatas 18 tahun) $<5,5 \mathrm{~mm}$ (Amini et al., 2013). Responden yang diambil seluruhnya adalah > 18 tahun, sehingga tidak mempengaruhi hasil penelitian.

Distribusi sampel menurut nilai IMT (intima media thickness) homogen sebelah kanan, sehingga tidak banyak berpengaruh pada hasil analisis data. Sedangkan IMT kiri didapatkan nilai $\mathrm{p}<0,05$, berbeda signifikan antara dua kelompok (tidak homogen). Belum adanya pustaka yang menjelaskan hubungan antara IMT dan pelebaran ONSD dapat menjadi keterbatasan penelitian ini. Penelitian sebelumnya hanya menyebutkan bahwa peningkatan IMT menunjukkan adanya risiko penyakit stroke/infark miokard sebesar 3,87 kali lipat dibanding IMT normal (Rajajee et al., 2010)

Distribusi sampel menurut tekanan darah (sistolik/diastolik) tidak homogen (tabel 1). Belum adanya pustaka yang menjelaskan 
Avalaible online at https://journals.ums.ac.id/index.php/biomedika, Permalink/DOI: 10.23917/biomedika.v11i2.8466

Biomedika, ISSN 2085-8345

hubungan antara tekanan darah dan pelebaran

ONSD dapat menjadi keterbatasan penelitian

ini. Adanya perbedaan tekanan darah yang signifikan diantara dua kelompok dapat disebabkan oleh penyakit yang mendasarinya.

Gangguan peredaran darah otak akan mengaktifkan sistem autoregulasi

serebrovaskuler sebagai kompensasi, terutama pada keadaan aliran darah otak terganggu/iskemik (Dunn, 2002).

Nyeri kepala ringan mempunyai distribusi terbanyak dari sampel (80\%), hal ini dapat disebabkan karena pasien telah mendapatkan terapi. Tidak adanya data mengenai terapi anti nyeri, anti edema (kortikosteroid) maupun obat yang bersifat osmotik/diuresis merupakan keterbatasan dari penelitian ini. Menurut onsetnya, nyeri kepala akut mempunyai prosentase lebih besar daripada nyeri kepala kronis, hal ini bisa disebabkan oleh jenis penyakit yang mendasarinya.

Berdasarkan jenis penyakit, stroke non hemoragik menempati jumlah terbanyak dari sampel (36\%) dan paling sedikit yaitu SAH (3\%). Adanya perbedaan jumlah sampel pada masing-masing diagnosis dapat merupakan keterbatasan pada penelitian ini.
Analisis nilai ONSD pada pasien nyeri kepala dan responden normal menunjukkan adanya perbedaan yang pada pasien nyeri kepala dan responden normal dengan $\mathrm{p}<0,05$ (tabel 2).

Penelitian (Rajajee et al., 2010) menyebutkan diagnosis bervariasi (ICH, Stroke iskemik, TBI, meningitis tuberculosa), didapatkan adanya dilatasi ONSD dengan nilai $>5 \mathrm{~mm}$ dengan nilai dan turun $<5 \mathrm{~mm}$ setelah dekompresi dengan hemikraniektomi $(\mathrm{p}=$ 0,028). Penelitian ini juga menyebutkan bahwa dilatasi ONSD berkorelasi dengan didapatkannya tanda-tanda peningkatan TIK pada CT Scan.

Peningkatan ONSD dapat disebabkan oleh beberapa hal. Pada pasien tanpa peningkatan tekanan intrakranial, peningkatan ONSD dapat terjadi akibat neuritis optikus, kista arachnoid pada nervus optikus, trauma nervus optikus, massa pada sinus cavernosus atau orbita anterior. Sedangkan pada pasien dengan peningkatan tekanan intrakranial dapat terjadi akibat tumor atau space occupaying lesion (SOL) pada sistem saraf pusat, pseudotumor serebri, penurunan resorpsi LCS (Liquor Cerebrospinal) misalnya pada trombosis sinus venosus, proses inflamasi, 
meningitis dan SAH (subarachnoid haemorrhage), juga pada peningkatan produksi LCS (tumor), obstruksi sistem ventrikuler, edema cerebri, encephalitis, dan raniosinostosis (Girisgin et al., 2007).

Beberapa studi menunjukkan adanya korelasi antara peningkatan ONSD dan peningkatan tekanan intrakranial pada pasien dengan trauma kepala berat, perdarahan intrakranial dan hipertensi intrakranial idiopatik. Sebaliknya, penurunan ONSD ditemukan pada pasien dengan hipotensi intrakranial idiopatik. Hubungan peningkatan TIK dengan lebar ONSD dapat dijelaskan adanya kelanjutan meningen dan ruang subarachnoid ke sekitar nervus optikus (Bäuerle et al., 2013).

Penelitian yang dilakukan pada 6 anak pada masing-masing kelompok menyebutkan bahwa perbedaan ONSD pada anak normal dan peningkatan TIK berbeda secara signifikan dengan rata-rata 3,3 $\pm 0,6(2-4,35)$ pada anak normal dan rata-rata $5,6 \pm 0,6(4,55-7,6)$ pada anak dengan peningkatan TIK (Bouguetof $e t$ al., 2014).

Penelitian di India, Shirodkar (2014) yang membandingkan antara pemeriksaan ONSD dengan sonografi dan MRI menyebutkan bahwa sonografi ONSD dapat digunakan sebagai deteksi awal peningkatan TIK, murah dan dapat dievaluasi ulang dengan sensitifitas $75 \%$ - $85 \%$ dan spesifitas $100 \%$ (Shirodkar et al., 2014).

Pada tabel 3 disebutkan bahwa nilai ONSD pada pasien nyeri kepala ringan dan berat menunjukkan perbedaan yang signifikan dibandingkan kelompok normal, sedangkan pada nyeri kepala sedang tidak terdapat perbedaan.

Berdasarkan tabel 3 baik nyeri kepala akut maupun nyeri kepala kronis mempunyai nilai ONSD yang berbeda signifikan dibandingkan dengan responden normal (tabel 3). Dunn (2002) menyebutkan bahwa peningkatan TIK akibat gangguan liquor cerebrospinal dapat terjadi secara akut maupun kronis.

\section{SIMPULAN}

Pada penelitian ini terdapat perbedaan nilai ONSD pada responden normal dan pasien nyeri kepala di RS. X (nilai $\mathrm{p}<0,005$ ) dengan mean lebih tinggi pada pasien nyeri kepala $(5,2$ $\pm 0,95 \mathrm{~mm})$ dibanding responden normal $(4,2$ $\pm \quad 0,66 \mathrm{~mm}), \quad$ sehingga dapat ditarik kesimpulan bahwa peningkatan tekanan intrakranial pada pasien nyeri kepala dapat 
dideteksi dini dengan pemeriksaan optic nerve

sheath diameter (ONSD).

\section{DAFTAR PUSTAKA}

Amini, A., Kariman, H., Arhami-Dolatabadi, A., Hatamabadi, H.R., Derakhshanfar, H., Mansouri, B., Safari, S., and Eqtesadi, R. 2013. Use of the sonographic diameter of optic nerve sheath to estimate intracranial pressure. The American Journal of Emergency Medicine. Elsevier, 31(1), pp: 236-239.

Bäuerle, J., Schuchardt, F., Schroeder, L., Egger, K., Weigel, M., and Harloff, A. 2013. Reproducibility and accuracy of optic nerve sheath diameter assessment using ultrasound compared to magnetic resonance imaging. $B M C$ Neurology, 13(1), p: 187.

Beare, N.A.V., Glover, S.J., Lewallen, S., Taylor, T.E., Harding, S.P., and Molyneux, M.E. 2012. Prevalence of raised intracranial pressure in cerebral malaria detected by optic nerve sheath ultrasound. The American journal of tropical medicine and hygiene. 87(6). pp: $985-988$.

Bouguetof, H., Elhalimi, K., Negadi, M.A, Boumendil, D., and Mentouri, Z. 2014. Sonographic Evaluation of Optic Nerve Sheath Diameter (ONSD) in Children with Raised Intracranial Pressure (RICP) Preliminary Results. Pediatric Critical Care Medicine. 15(40).

Dunn, L. T. 2002. Raised Intracranial Pressure. Journal of Neurology, Neurosurgery \& Psychiatry. BMJ Publishing Group Ltd, 73(suppl 1), pp: i23--i27.
Fernández-de-las-Peñas, C., Arendt-Nielsen, L. and Gerwin, R.D. 2010. Tension-Type and Cervicogenic Headache: Pathophysiology, Diagnosis, and Management. Massachusset: Jones and Barlet Publisher.

Fuller, K., Ian, L. and Geraint, B. 2010. Neurology and Neurosurgery Illustrated. Glasgow: Churchill Livingstone.

Girisgin, A.S., Kalkan, E., Kocak, S., cander, B., Gul, M., and Semiz, M. 2007. The role of optic nerve ultrasonography in the diagnosis of elevated intracranial pressure. Emergency medicine journal : EMJ. BMJ Group, 24(4), pp: 251-254.

Hansen, H.C., Laqreze, W., Krueger, O., and Helmke, K. 2011. Dependence of the optic nerve sheath diameter on acutely applied subarachnoidal pressure - an experimental ultrasound study. Acta Ophthalmologica. John Wiley \& Sons, Ltd (10.1111). 89(6). pp: e528-e532.

Rajajee, V., Thyagarajan, P., and Rajagopalan, R.E. 2010. Optic nerve ultrasonography for detection of raised intracranial pressure when invasive monitoring is unavailable', Neurology India, 58(5).

Shirodkar, C.G., Rao, S.M., Mutkule, D.P., Harde, Y.R., Venkategowda, P.M., and Mahesh, M.U. 2014. Optic nerve sheath diameter as a marker for evaluation and prognostication of intracranial pressure in Indian patients: An observational study. Indian journal of critical care medicine: peerreviewed, official publication of Indian Society of Critical Care Medicine. India, 18(11), pp: 728-734. 